This item was submitted to Loughborough's Research Repository by the author.

Items in Figshare are protected by copyright, with all rights reserved, unless otherwise indicated.

\title{
Challenging generalisations: Leveraging the power of individuality in support group interactions
}

\section{PLEASE CITE THE PUBLISHED VERSION}

https://doi.org/10.1017/S0047404520000603

\section{PUBLISHER}

Cambridge University Press (CUP)

\section{VERSION}

AM (Accepted Manuscript)

\section{PUBLISHER STATEMENT}

This article has been published in a revised form in Language in Society https://doi.org/10.1017/S0047404520000603. This version is published under a Creative Commons CC-BYNC-ND. No commercial re-distribution or re-use allowed. Derivative works cannot be distributed. ( The Author.

\section{LICENCE}

CC BY-NC-ND 4.0

\section{REPOSITORY RECORD}

Pino, Marco. 2020. "Challenging Generalisations: Leveraging the Power of Individuality in Support Group Interactions”. Loughborough University. https://hdl.handle.net/2134/11953755.v1. 
Pino (2021) - Challenging generalisations

\title{
Challenging generalisations: Leveraging the power of individuality in support group interactions ${ }^{1}$
}

\section{MARCO PINO}

Loughborough University, UK

\begin{abstract}
Explicit generalisations are statements that attribute a characteristic to all members of a social category (e.g. drug users). This article examines the tensions and negotiations that the use of generalisations prompts within support group interactions. Generalisations are practices for the cautious implementation of delicate actions. They can be used to convey perspectives on group members' experiences by implication (without commenting on them directly), by virtue of those members belonging to the category to which a generalisation applies. At the same time, generalisations can misrepresent some individual cases within that category. Using conversation analysis, the article investigates how generalisations are deployed, challenged, and then defended in support group interactions. These analyses identify a tension between utilising the sense-making resources that category memberships afford, and the protection of its members from unwelcome generalisations. Data consist of recorded support-group meetings for people recovering from drug addiction (in Italy) and for bereaved people (in the UK). (Bereavement, conversation analysis, delicacy, drug addiction, generalisation, individuality, membership categorisation, morality, support groups)*
\end{abstract}

\section{INTRODUCTION}

Central to the organisation of social interaction are people's explicit and implied orientations to their own and others' memberships in social categories (Sacks 1992). People ascribe themselves and others to social categories along several dimensions, including gender, ethnicity, age, occupation, and various life circumstances amongst others. They organise their social actions with reference to cultural understandings about social categories and their

\footnotetext{
${ }_{1}^{1}$ Pino, M. (2021). Challenging generalisations: Leveraging the power of individuality in support group interactions. Language in Society, 50(5), 695-722. https://doi.org/10.1017/S0047404520000603
} 
properties (Schegloff 2007a; Stokoe 2012). One way in which people mobilise cultural understandings about categories and their members is the use of explicit generalisations: statements that attribute a characteristic to the members of a category. Using the methodology of conversation analysis (Sidnell \& Stivers 2013) to examine two sets of support-group interactions, this article investigates cases where group members challenge generalisations by invoking individual cases that do not conform to them. This practice leverages the power of individuality (the normative expectation that individual members' specificities should be acknowledged and respected) to limit the pervasiveness of generalised understandings of the members of a social category. The article further identifies ways in which participants attempt to reconcile discrepancies between generalisations and the individual cases that they allegedly misrepresent.

\section{Membership categorisation and generalisations}

Practices of membership categorisation involve displaying understandings about oneself and others as members of a social category (Sacks 1992; Schegloff 2007a; Stokoe 2012). Studies of social interaction in the traditions of ethnomethodology (Heritage 1984b), conversation analysis (Sidnell \& Stivers 2013), and discursive psychology (Edwards 1997) have investigated how people employ categorisations within their naturally occurring interactions. One key message from this research is that people mobilise category-based understandings of themselves and others in order to accomplish specific social actions (Edwards 1991; Schegloff 2007b). For example, there is evidence that people associate category memberships with entitlements to specific kinds of action, such as assessing people (Raymond \& Heritage 2006) and complaining about them (Sharrock \& Turner 1978; Stokoe 2009). Entitlements to action are a subset of the larger range of attributes that people associate with category memberships (Sacks 1992; Hester \& Eglin 1997; Schegloff 2007a; Stokoe 2012). These category-attribute associations are based on the common-sense assumption that members of a category will share some qualities (at least when they act as incumbents of the category). For this reason, the mobilisation of a category and its attributes implies some level of generalisation about the members of the category. For example, Stokoe (2009) documented the case of a council worker contacting a mediation service on a woman's behalf. To convey the woman's limited ability to advocate for herself, thereby accounting for calling on her behalf, the council worker reports that 'she is eighty-three' (2009:83). This invocation of age implies a generalised understanding about how people of a certain age are likely to be. 
By contrast to cases where generalisations are implicitly conveyed, people can produce explicit generalisations: statements that 'associate members of a category with a commonly known or typical attribute or set of attributes' (Whitehead 2018:293). Prior research has documented that generalisations can attract challenges. Robles (2015) showed that racial generalisations can be challenged through sarcastic formulations that expose their overgeneralising nature (e.g. by responding to 'Mexicans don't drink tea, they drink beer' with 'All they drink is beer!'; 2015:400). Whitehead (2018) documented that racial generalisations can be challenged by denouncing the fact that they indiscriminately attribute the same characteristics to all members of a category (e.g. by responding to 'the African community [in South Africa] they are brought up with hate' with 'You can't generalise like that'; 2018:294). It should come as no surprise that generalisations can attract challenges. Generalisations make explicit, and thus available for challenge, understandings that are only implicitly conveyed through other categorising practices (e.g. when describing someone as being 'eighty-three'; Stokoe 2009). Whitehead's (2018) and Robles' (2015) studies document how generalisations can be challenged on the basis that they explicitly extend the same features to all members of a category. Implicit in 'You can't generalise like that' (Whitehead 2018) is the understanding that a generalisation can misrepresent individual cases. This misrepresentation can be denounced in order to undermine the action that a generalisation implements.

In this article, I document a different and previously unexamined practice for challenging a generalisation: invoking an individual case that does not conform to it. Through this practice, participants challenge the validity and applicability of generalised understandings about the members of a social category. The next section provides background for understanding the importance of these negotiations within support-group interactions.

\section{Support groups}

Support-group interactions involve people meeting to discuss difficulties and life circumstances they recognise as shared, to exchange information, to discuss problems and solutions, and to socialise (Steinberg 2004). Meetings involve various degrees of structuring and can be facilitated by paid staff or unpaid volunteers.

Support-group work entails building a sense of sharedness, often referred to as 'being on the same boat' (Steinberg 2004). Prior research has shown that this involves practices of categorisation whereby members are treated, and also come to recognise themselves as members of a social category (Wootton 1977; Sacks 1992; Pollner \& Stein 1996). Sharing a 
category membership allows participants to access interpretive resources to make sense of their experiences. Use of these resources entails implicit or explicit generalisations. Pollner \& Stein (1996) documented how senior members of Alcoholic Anonymous (AA) use narratives to 'map' the social terrain for newcomers, that is, to socialise them into ways of making sense of their own experiences. Amongst various mapping practices, Pollner \& Stein (1996:201-211) register AA members' use of 'general or summary statements [such as] "Like so many other alcoholics, I started drinking in the Navy"',

Generalisations enable support-group members to navigate a practical problem: conveying perspectives on others' experiences (e.g. through interpretations, explanations, and evaluations) without speaking about them directly. Therefore, generalisations are methods for formulating DELICATE actions in cautious ways (on delicacy, see Lerner 2013). This form of caution has its roots in a broader social orientation to the 'ownership' of individual experiences (Sacks 1984; Peräkylä \& Silverman 1991; Lerner 1996; Heritage 2011); avoiding directly commenting on someone's experiences pays deference to their primary right to define their nature. This social orientation has special relevance within support-group cultures, in which participants are commonly expected to avoid commenting on one another's experiences directly (e.g. by interpreting or evaluating them; Steinberg 2004). Discussions of individual members' experiences are also delicate because they can raise considerations of moral responsibility and blame (these have been documented in different support-group settings; see Auburn 2005; Logren, Ruusuvuori, \& Laitinen 2017; Pino 2018). Therefore, it makes sense for group members to convey their perspectives on others' experiences indirectly (on indirectness, see Drew 2018), and generalisations enable them to do so. Generalisations convey claims that apply to co-present participants by implication, by virtue of their membership in the social category to which a generalisation applies. Generalisations are therefore methods for the cautious delivery of delicate, morally sensitive actions.

Generalisations invoke and reflexively reinforce category-based cultural understandings that participants share. Their use reflects and invigorates a key aspect of support-group culture - a sense of 'being on the same boat' - and mobilises it for the implementation of institutionally relevant actions. At the same time, generalisations are vulnerable to challenge on the basis that they can misrepresent some of the individual cases to which they apply. Kitzinger (2000) examined how members of a support group for women with breast cancer challenged a particular generalisation (conveying that 'positive thinking' benefits cancer patients' health). One type of challenge involved invoking the existence of individual cases that did not conform to the generalisation. Kitzinger's finding resonates with 
the tensions I examine in this article. On the one hand, generalisations provide members with 'maps' (Pollner \& Stein 1996), which they can use to make sense of their problems and to (re)affirm a sense of sharedness. On the other hand, generalisations can misrepresent individual circumstances; they can be challenged on this basis, thus undermining the actions they implement.

The analytic section of this article examines sequences of talk in support-group interactions where a participant uses a generalisation, another participant challenges it by invoking an individual case that does not conform to it, and then the one who introduced the generalisation undertakes to defend it. In terms of contributions, these analyses bring into focus an essential problem for participants in support-group interactions and, quite likely, in other settings where recognising oneself and others as members of a social category constitutes an important sense-making and action-mobilising resource. What is at stake for the participants is not establishing whether or not they should be treated as members of a certain social category but, rather, negotiating whether (or the extent to which) specific category-based understandings should be generalised to all members of the category.

\section{DATA AND METHODS}

This study employs conversation analysis (CA; Sidnell \& Stivers 2013). CA is an approach to studying how people accomplish social activities through talk and other interactional resources. $\mathrm{CA}$ is grounded in systematic examination of recordings of naturally occurring interactions. Examination of interactional practices is based upon inspecting their placement within sequences of actions as well as their compositional features (e.g. choice of words, prosody, etc.). Conversational data is transcribed using notations capturing several aspects of participants' talk including sequential (e.g. silences and overlaps) and compositional features (e.g. intonation, speed of talk, loudness; Jefferson 2004).

For this study, I analysed two data sets. The first comprises twenty-four audio-visually recorded facilitated group meetings for people recovering from drug addiction (lasting twentysix hours in total). These meetings were recorded in three residential and semiresidential therapeutic communities in Italy (participants speak Italian). The number of facilitators per meeting varied from one to four; the number of clients from three to sixteen. I refer to these as 'TC data'. The second set consists of four audio-recorded facilitated group meetings for bereaved people (lasting 6.5 hours in total). These meetings were recorded in a support group run by a UK charity (participants speak British English). Two or three volunteers were present 
in each meeting; one of them fulfilled the role of facilitator. The number of clients varied between five and eight. I refer to these as 'BRV data'. The reason for employing both data sets is their accessibility to the author. Whilst I do not make claims about the generalisibility of the findings to other settings, the presence of the target phenomena in both data sets suggests that they are not confined to one particular setting.

The analyses reported here are from a broader study on actions that group members implement by mentioning their experiences. A subset of instances consists of cases where members invoke their individual case in order to challenge a generalisation. The analysis revealed that members also invoke the case of someone they know (e.g. a friend who is not part of the group) to implement the same action (challenging a generalisation). Therefore, I added these cases to the collection, which comprises twenty-one instances in total. The examples in this article illustrate findings that hold across the collection. Although the wider data set includes video-recorded and audio-recorded meetings (the latter were audio-recorded because the participants did not wish to be filmed), most examples in this article come from audio-recorded meetings (only extracts (10)-(11) are from a video-recorded meeting). This is because the audio-recorded sessions happened to contain the most concise examples of the phenomena examined in this article. ${ }^{1}$

In line with the theoretical and methodological underpinnings of CA, I do not take group members' use of generalisations to reflect inner psychological states, such as stereotypical or prejudiced attitudes (Billig 1985). Rather, I examine generalisations as interactional resources that group members use to accomplish actions within their interpersonal interactions (Zimmerman \& Pollner 1970).

\section{ANALYSIS}

\section{Generalisations}

Generalisations 'associate members of a category with a commonly known or typical attribute or set of attributes' (Whitehead 2018:293). Two features contribute to the recognisability of generalisations: invocation of a social category and attribution of a characteristic to the members of that category. Participants invoke a social category either explicitly, through a reference term (e.g. 'widower'), or implicitly. In the latter case, they use general reference terms ('someone', 'everyone') or pronouns (the impersonal 'one' and the generic 'you'), but the context of the talk and the focus of the turn make it clear that a specific category is being invoked. 
In the support-group meetings, facilitators and clients use generalisations that attribute characteristics to the members of a category to which the clients are taken to belong: people with a shared history of drug use (TC data) and bereaved people (BRV data). Generalisations are used within two activities: discussing an individual client's problems or circumstances (e.g. extracts (3)-(4)) and debating broader aspects of the problems and circumstances that the clients share (e.g. extract (1)). Within these activity contexts, facilitators and clients use generalisations in order to interpret, assess, or explain the types of problems or circumstances that the clients describe. Generalisations enable participants to accomplish these actions without speaking about anyone's case directly. Generalisations convey claims that apply to the clients by implication, by virtue of their membership in the category to which a generalisation applies.

Extract (1) is a first illustration (TC data). The clients have been discussing how their parents reacted upon discovering that they used illegal drugs (data not shown). At lines 1-5, Lidia (a client) proposes that in those cases parents blame themselves for their children's actions. She does so by animating the hypothetical reaction that she could have if she found herself in that situation (lines 3-5). Enrico (another client) subsequently proposes that people start using drugs by socialising with "the wrong people" (i.e. people who use drugs, lines 912). This is a generalisation.

(1) (IntV4 31:04; TC data) 'Wrong people'

Two clients, Lidia (C-Lid) and Enrico (C-Enr), and one facilitator, Marta (F-Mar), speak in this extract. Another facilitator and another client are present.

1 C-Lid: Aheh sarebbe un fallimento- >cioè< io lo vivrei come un fallime:nto. PTC be-CND.3s a failure I.mean 1S.N 3S.A live-CND.1S as a failure

'Aheh it would be a failure- >I mean $<$ I would experience it as a failure.'

$2(0.2)$

3 C-Lid: “Colpa m[ia. L’ho cresciuto ma:le. Che educazione le ho da:to. fault my 3S.A=have-1S raise-PSTP badly what education 3S.A have-1S give-PSTP “"((It was)) my fault. I didn't raise him properly. What kind of education did I give her.'

4 F-Mar: $\quad[\mathrm{Mm}$.

PTC

'Mm.'

5 C-Lid: Cosa: h[hh cosa:::] gli ho fatto manca:re. Come mai è arrivato lì?" what what 3S.D have.1s make-PSTP miss-INF how come be.3S arrive-PSTP there 
'What .hhh wha:::t did I not give him. Why did he get there?",

6 S-Mar: $\quad[(($ coughs $))]$

$7 \quad(0.4)$

8 F-Mar: $\mathrm{Mm}_{-}$

9 C-Enr: Ma: alla fine ma ne:(i) maggior parte dei casi:: (1.1) non >cioè::< but in=the end but in-the major part of=the cases not I.mean 'But in the end in the majority of cases (1.1) >I mean<'

10 per esempio >cioè< a me non mi è mai mancato niente. for example I.mean to 1S.A not 1S.D be-3S never lack-PSTP nothing 'for example $>$ I mean $<$ I was never deprived of anything.'

11 Però alla fine uno:: frequentando compagnie sbagliate, arriva lo stesso but in=the end one frequent-GER companies wrong arrive-3s the same 'But in the end when one hangs out with the wrong people, they end' a: (.) .hh a fare certe cose.

to to do-INF certain things

'up doing (.) .hh certain things anyway.'

Enrico projects a possible generalisation at line 9 ('in the majority of cases'). He abandons it to exclude child neglect as an explanation for his own drug use at line 10 (responsive to Lidia's comment at line 3). Enrico goes on to propose an alternative explanation, this timxe in the form of a generalisation, about drug users (lines 11-12). Enrico's statement (lines 11-12) is built as a generalisation through the use of the impersonal pronoun uno 'one'. It is clear that this refers to drug users because of the context of the talk (about drug users) and the focus of Enrico's turn (explaining drug use; the euphemistic 'doing certain things', line 12, being hearable as a reference to drug use within the ongoing discussion). This analysis is supported by Lidia's response (see extract (2), lines 20-22), where she treats Enrico's turn as proposing a generalised explanation for how people start to use drugs.

In the context of Lidia's proposal that parents blame themselves for their children's drug use, Enrico's explanation exonerates parents; he proposes that socialising outside the home, rather than family life, leads to drug use. His explanation therefore manages the moral implications raised by Lidia's remark. Using a generalisation enables Enrico to extend this explanation beyond his own case whilst avoiding referring to anyone's case in particular. Enrico's use of a generalisation is also fitted to the generalised nature of the discussion in 
Pino (2021) - Challenging generalisations

progress (e.g. Lidia's statement at lines $1-5$ is about parents in general). Despite this, Lidia challenges Enrico's generalisation in (2) below. I examine this in the next section.

\section{Challenging generalisations by invoking individual cases}

Whilst generalisations solve a practical problem - conveying interpretations, explanations, and evaluations that can apply to clients without speaking about them directly-they generate another. Generalisations attribute a characteristic to all members of a category. They can be taken to mispresent some individual cases within that category, and they can be challenged on that basis. Clients challenge generalisations and the actions that they implement by invoking an individual case (their own or that of someone they know) that does not conform to them. In these cases, clients are not resisting being treated as members of a category (e.g. as drug users). Rather, they are challenging the fact that a specific cultural understanding has been extended to all members of the category. In doing so, they tacitly convey and reflexively exploit the normative expectation that category-based understandings should not be used in ways that misrepresent the individual members of a social category. In this sense, they leverage the power of individuality to draw a line that limits the pervasiveness of generalised understandings about the members of a category. Across all cases in the collection, clients' challenges also manage moral implications associated with generalisations and the actions they implement.

It is important to clarify that clients never challenge generalisations in an abstract, decontextualised way. Rather, they invoke an individual case to challenge the generalisation AND the particular action that the generalisation implements in a given instance. The two aspects are inextricably linked.

Client use two types of challenge: validity challenges, which invoke an individual case to undermine the overall validity of a generalisation, and applicability challenges, which only contest the applicability of a generalisation to one case, leaving wider implications for its overall validity unstated. I examine both in what follows.

Validity challenges. Extract (2) is a direct continuation of extract (1). We come back just after Enrico has produced the 'wrong people' generalisation.

(2) Direct continuation of (1): 'Wrong people' 
Pino (2021) - Challenging generalisations

14 C-Lid: No. №. [№.

no no no

'№. №. №.'

15 C-Enr:

[Sì in[vece]=

yes instead

'I'm telling you yes='

16 C-Lid:

$[\mathrm{N}: \mathrm{o}]=$

no

'N:O='

17 C-Enr: in[vece sì:?]

instead yes

'I'm telling you yes?'

18 C-Lid: [个non dire]:- (.) no.=

not say-IMP.2s no

‘个don’t say:- (.) no.='

19 C-Enr: =Inve[ce sì:[:?

instead ye::s?

'=I'm telling you ye::s?'

20 C-Lid: [io non-[.hh va beh. A te (.) è successo $\uparrow$ questo. Perché

1S.N not- go-3S well to $2 \mathrm{~S}$.A be-3S happen-PSTP this because

'I ((didn't)) .hh alright. This happened to you. Because'

21 a me la Babi, hh per esempio che è uscita sempre con noi che ci

to 1S.A the NAME for example who be-3s go.out-PSTP always with 1P.A who 1P.RFL

'to me for example Babi, .h who always went out with us when we'

22

dogravamo dalla mattina alla sera, hh non si è mai droga:[ta.

take.drugs-IPF.1P from.the morning to.the evening not 3S.RFL be-3S never take.drugs-PSTP

'were taking drugs all the time, .hh she never used drugs.'

Lidia firmly rejects Enrico's generalisation (line 14) and Enrico supports it (line 15); they repeat the pattern at lines 16-19. At line 20, Lidia arguably starts to support her rejection by invoking her own case (io non 'I ((didn't))'), which she abandons. Next, she produces a concessionary va beh 'alright' and a validity challenge. The contrast $A$ te è successo questo. Perché a me... 'This happened to you. Because to me...' (lines 20-21) frames Lidia's action as challenging the validity of Enrico's generalisation. She concedes that Enrico's generalisation can adequately portray his own case, but she contests its validity for drug users in general. 
Lidia does so by mentioning the case of a friend who never used drugs despite socialising with people who did (lines 21-22).

In this instance, the discrepant case that Lidia invokes is not that of a member of the category of drug users (she invokes one such case later in extract (14)). However, this case has implications for understanding the category of drug users. The challenge that this case conveys undermines the general validity of the 'wrong people' generalisation; in this way, Lidia's challenge makes relevant alternative explanations for drug use (and she introduces one later in extract (14)).

Lidia's challenge also manages some moral implications of Enrico's generalisation. The generalisation is vulnerable to being seen as relieving drug users from the responsibility for choosing a drug-user lifestyle (because they were led to it by others). Lidia's stark opposition appears to embody this treatment of Enrico's generalisation (although this only becomes explicit later, as shown in extract (14)). The therapeutic-community approach, which informs the TC group sessions examined in this article, promotes an ethos of personal responsibility, especially in terms of taking responsibility for one's own recovery (Pearce \& Pickard 2013). Lidia's challenge is a first step towards reinforcing that ethos.

Applicability challenges. These challenges formally target the applicability of the generalisation to one case, leaving broader implications for its validity unstated. Those who used a generalisation nevertheless orient to the damaging implications of these more circumscribed challenges for the validity of their generalisation. Extract (3) (BRV data) exemplifies this.

Christine has been talking about her son (data not shown). At lines 1-3 of extract (3), Christine reports that her son blames her for her husband's (and his father's) death. Amy, the facilitator, starts to make a connection with topics discussed earlier in the meeting (lines 3-4) but abandons this when Christine expands her turn with a generalisation about people's need to blame somebody (lines 6-8). Following an 0.7-second silence, Christine recompletes her turn with "I don't know" (line 10). Amy then contests the idea that Christine is responsible for her husband's death (line 11). Then, Amy proposes that blaming someone for the death of a loved one, as Christine's son reportedly does, helps people find an explanation for that death (lines 11-19). This is a generalisation, which is followed by an applicability challenge.

(3) (BRV1-1 22:31; BRV data) 'Blaming somebody' 
The volunteer facilitator (F-Amy) and two clients, Christine (C-Chr) and Donald (C-Don), speak in this extract. Four other clients and two other volunteers are present.

1 C-Chr: I think he re he really (b-) blames: (0.2) 个me for (.) my husband's

$2 \uparrow$ death which is just absolutely ridiculous?. $\mathrm{hhh}[\mathrm{h}$

3 F-Amy: [But is- isn't

4 [that interesting that we [just

5 ???: $[\mathrm{Mm}$

6 C-Chr: [But I suppose they've [got to blame=

7 F-Amy: [Yeah

8 C-Chr: = $\uparrow$ somebody haven't they.

$9 \quad(0.7) /(($ someone coughs $))$

10 C-Chr: I don't know?

11 F-Amy: tk (0.2) Well it's not $\uparrow$ true but it (1.5) that as I just said, it's often a way of $(0.4)$ someone's mind $\mathrm{s} \uparrow$ :ettling=

13 C-Chr: =Well ye[ah

14 F-Amy: [on an explana[tion but (.)

15 C-Chr: $\quad[\mathrm{Mm}$ :

16 F-Amy: the problem is (0.3) that then makes everything wor[se

17 C-Chr:

[Mm:.

19 F-Amy: (tk) ${ }^{\circ}$ for $^{\circ}(\mathrm{k})(0.3)$ the whole family, and $(0.2)$

21 C-Chr:

$[\mathrm{Mm}:$

Amy's statement (lines 11-19) is built as a generalisation through the generic reference to 'someone' (line 12). It is clear that this refers to bereaved people (a category to which the clients and their relatives belong, including Christine's son) through the context of the talk and the focus of Amy's statement (on reasons why bereaved people blame others for the death of someone to whom they are attached). Her generalisation implements an explanation for the kind of predicament that Christine is experiencing. Amy explains Christine's son's behaviour by using a common account, shared in much bereavement-support culture and encapsulated in Kübler-Ross' (1969) classic work on bereavement, that many bereaved people alleviate their grief by blaming others for the death of someone to whom they are attached. In this way, Amy suggests that Christine's son's actions might not be motivated by an intention to harm Christine 
but, rather, be a way of coping with the pain he is also experiencing. This explanation amounts to suggesting that Christine's son is not to blame. This is a delicate operation because moral judgments about the actions of Christine's son fall primarily within Christine's own 'territory of experience' (Heritage 2011). However, using a generalisation enables Amy to avoid speaking about Christine's son directly whilst conveying a statement that has implications for explaining his actions.

This analysis is supported by Donald's response at lines 24-31 in (4), where he treats Amy's statement as a generalisation about bereaved people, including himself. He does so by challenging the APPLICABILITY of the generalisation to his own case.

(4) Direct continuation of (3): 'Blaming somebody'

22 C-Don:

[Is-

23

$(0.3)$

24 C-Don: am I then so (0.6) $\uparrow$ different from (1.2) you know (0.8) other people? .hh (.) Because when my father passed away, (0.6) I was $\uparrow$ devastated.

26 F-Amy: Mm.

27

28 C-Don: A:nd at that moment I had two brothers and they were $\uparrow$ devastated as

29 个well.

30

31 C-Don: But $\uparrow$ neither of us blamed $\uparrow$ mother.

Donald's “am I then so (0.6) 个different from (1.2) you know (0.8) other people?” (line 24) frames Donald's action as challenging the applicability of Amy's generalisation to his own case (rather than its overall validity). However, Donald's question (line 24) rhetorically implies that he is NOT different from other people and, therefore, that there must be others to whom the generalisation does not apply. Donald's applicability challenge therefore has validity-challenge implications for Amy's generalisation (to which she later orients; see extract (6)). Donald substantiates his position by reporting that he did not blame his mother for the death of his father (lines 25-31). This contrasts with Christine's case of being blamed by her son for her husband's death (a case that Amy treated as supporting her generalisation).

Donald's challenge addresses moral considerations associated with Amy's generalisation and the explanation it implements. Although Amy's generalisation can be understood as 'absolving' Christine's son, it still proposes that bereaved persons tend to blame 
others for the death of someone to whom they are attached, which can be regarded as a reprehensible thing to do. By reporting that he did not blame his mother for the death of his father, Donald removes himself from what can be treated as a morally compromised position. ${ }^{2}$

Discussions of the causes of the clients' problems occupy a prominent place within support-group interactions. Extracts (1)-(4) have illustrated how these sometimes entail negotiations about whether certain category-based understandings should be extended to all members of a category. The next section examines what happens next in these negotiations (i.e. after a challenge).

\section{Responses to challenges}

Validity and applicability challenges present those who used a generalisation with a dilemma. Withdrawing endorsement to the generalisation and the action it implements is problematic because it purportedly applies to a number of cases, not just the case that has been invoked against it. Defending the generalisation and the action it implements is also difficult because this can be seen as disregarding the specificity of the individual case invoked against it. A dilemma emerges in these cases. What is more important in support groups? Is it preserving generalisations, the category-based understandings they channel, and the actions they implement? Or is it recognising the distinctiveness of individual cases? Are there ways of meeting both requirements?

In the TC and BRV data, those who have proposed a generalisation respond to a subsequent challenge by defending the generalisation and the action it implements. They do so in three ways: separating the generalisation from the individual case, altering the meaning of the individual case, and specifying the generalisation. These solutions represent different ways of managing the dilemma occasioned by a challenge, and they have different consequences. In some cases, preserving the action that a generalisation implements entails restricting its applicability to a smaller set of cases within a category (as opposed to all cases), therefore partly undermining its status as a generalisation.

Separating the generalisation from the individual case. A generalisation can be defended by proposing that it does not apply to the case invoked against it. This allows one to defend it without modifying it (to accommodate the individual case) and without altering the individual case (to assimilate it to a generalisation). A line is drawn to separate the generalisation and the 
Pino (2021) - Challenging generalisations

individual case so that any challenge implications of the latter are deactivated. This can be done by treating the individual case as an exception, as in extract (5) (a continuation of extract (2)).

(5) Direct continuation of (2), end of line 22 repeated: 'Wrong people'

22 C-Lid: non si è mai droga:[ta.

not 3S.RFL be-3S never take.drugs-PSTP

'she never used drugs.'

23 C-Enr:

[Eh ma anche un mio ami:co_

PTC but also a my friend

'Right but also a friend of mine_'

24

25 C-Enr: Il Teo.

the NAME

'Teo.'

26 C-Lid: $\underline{E}[\mathrm{~h}$ !

PTC

'Right!'

27 C-Enr: [Quello che ho fatto venire [qua. that-M who have-1s make-PSTP come-INF here 'The one that I took here.'

In response to Lidia's invocation of her friend's case, Enrico invokes the case of a friend of his. The turn-initial Eh ma 'Right but' (line 23) frames this as opposing Lidia's viewpoint. With anche 'also' (line 23), Enrico conveys that his friend's case was the same as that of Lidia's friend (he never used drugs either, despite socialising with people who did). By volunteering this case, which does not conform to his own generalisation, Enrico implies that some disconfirmatory cases do not undermine the generalisation and the explanation it implements; they are exceptions. This operation is somewhat implicit, done by volunteering an additional case that does not conform to the generalisation. By contrast, in extract (6) (a continuation of extract (4)) the operation is explicit.

(6) Direct continuation of (4), line 31 repeated: 'Blaming somebody'

31 C-Don: But $\uparrow$ neither of us blamed $\uparrow$ mother.

32

33 F-Amy: No:. 
Pino (2021) - Challenging generalisations

34

35 F-Amy: Not- it doesn't happen all the time.

36

(.)

37 C-Don: $\mathrm{O}[\mathrm{h}$.

38 F-Amy: [But it's more common than you thi:nk.

39 C-Don: [O:h.

40 F-Amy: [And (.) I think that's all I wanted to [个say.

41 C-Don:

[O:h.

42 F-Amy: Ye[ah.

43 C-Chr: [Mm:.

In response to Donald's applicability challenge, Amy acknowledges the reality of Donald's case ("No", line 33). She then defends the validity of her generalisation by separating it from Donald's case (in doing so, she orients to the validity-challenge implications of Donald's applicability challenge). Amy's argument comes in three instalments, all registered by Donald as new information (lines 37, 39, and 41). ${ }^{3}$ Amy states that the generalisation does not always apply (thereby conveying that Donald's case is an exception; lines 35) but is nevertheless "more common than you think" (thereby supporting its validity; line 38). Amy further claims that this had been her position from the outset (line 40). Separating the generalisation allows Amy to defend the explanation it implements whilst concurrently acknowledging the reality of Donald's case.

Use of separating practices resonates with Sacks' observation that categories are 'protected against induction': 'you know that there are exceptions, and they do not involve you in modifying what you know' (1992:180). At the same time, though, acknowledging the existence of an exception has a concessionary quality and limits the scope of applicability of a generalisation. To some extent, the challenges examined here are successful in limiting the force of generalisations.

The separating practices examined so far allow one to defend a generalisation and the action it implements whilst respecting the reality of the individual case. A related practice is to propose that the discrepant case falls outside the remit of the generalisation. Before extract (7) (BRV data), the group have been discussing the theme of further companionship. Jim (a client) has suggested that it is inappropriate for widows and widowers to have another companion after the death of their partner (data not shown). He reinforces this view with a generalisation. 
(7) (BRV 2-1 16:30; BRV data) 'Looking for a nurse'

Three clients, Jim (C-Jim), Sharon (C-Sha), and Donald (C-Don), and the volunteer facilitator Peter (F-Pet) speak in this extract. Two other clients and two other volunteers are present.

1 C-Jim: A-and $\uparrow$ no: I- I $\uparrow$ think that $\mathrm{h}$ you knowh hy .hh that hh if you're a

2 个widower $\mathrm{h}$ I can understand a younger woman and perhaps a younger

3 ma:n. (0.5) $\uparrow$ Bu:t (.) you know, for $\uparrow$ o:lder $<$ people $>=$

Jim's statement is designed as a generalisation through the generic 'you' in 'if you're a widower" and the reference to "older people" (in context, older widows/widowers). In a previous part of the meeting, Donald (another client, whose wife had died) had shared that he would like to find a new partner (data not shown). Jim's generalisation implies a negative evaluation of that position. However, using a generalisation allows him to avoid criticising anyone directly, especially Donald. Sharon's response is clearly orientated towards the moral implications of Jim's generalisation:

(8) Direct continuation of (7): 'Looking for a nurse'

4 C-Sha: =W'1 I think it depends? Like you say $>$ I mean $<$ some older people-

$5 \quad>$ I mean< > like I say< a friend of $\uparrow$ mine, $(0.2) \mathrm{u}: \mathrm{m}$ when his wife died,

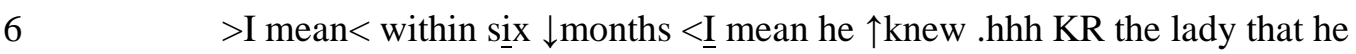

7 married, (.) I mean (.) you know they knew <hi:s $\uparrow$ wife knew her.=But.$h$

8 within $\uparrow$ six months then he'd married her? (.) And his $\uparrow$ son thought it

$9 \quad$ was $(0.2) \uparrow A W f u l(0.3)$ that his

10 [ $\uparrow \mathrm{da}: \mathrm{d}($.$) had married this: (.) [ \uparrow$ lady.=

11 ???: $\quad[\mathrm{Mm}:$

12 C-Don:

$[\mathrm{Mm} . \quad=\mathrm{Mm}$.

13 C-Sha: A:n:d: (.) and then $\uparrow$ after, (0.3) they were grateful becau:se his dạd

14 were ill? And Maggie really looked $\uparrow$ after him.

15 C-Don: Mm:.

16 F-Pet: $\operatorname{Mm}[$ :

17 C-Sha: $\quad[\uparrow$ you know. $=$

Sharon's action is framed as a validity challenge (line 4). "It depends" proposes that Jim's statement can hold true for individual cases but not universally as a generalisation. 
Sharon starts to substantiate this position with reference to "some older people" (line 4), but she abandons this and invokes the case of a friend who remarried six months after his wife's death (lines 5-6). Crucial to the challenge import of Sharon's story is that her friend's son reacted negatively to his father's marriage (lines 8-10) but was subsequently appreciative of it (lines 13-14). With this detail, Sharon's story subverts the moral position embodied in Jim's generalisation and the negative evaluation it implements. Jim's response follows in (9).

(9) Direct continuation of (8): 'Looking for a nurse'

18 C-Jim: = $=$ Well yeah, a- you [know, ] men of a $\uparrow$ certain a:ge=

19 C-Sha: [An:- ]

20 ???: $=\uparrow Y e[a h$.

21 C-Jim: [they're not looking for a $1 \uparrow:$ over. They're looking for a nu:rse.

22 ???: $\uparrow \mathrm{Mm}$

23 C-Don: Heh heh heh heh heh

Jim reconstructs the individual case as falling outside the scope of the generalisation. With the sarcastic “men of a certain age they're not looking for a lover. They're looking for a nurse" (line 18-21), Jim suggests that the case of Sharon's friend is not that of an authentic marriage, inspired by romantic feelings. For this reason, it does not invalidate the generalisation; it is irrelevant to it.

Jim's response sits at the boundary between the separating practices examined in this section and the practices examined in the next. Jim alters the meaning of the individual case. However, he does so in order to convey that the generalisation does not apply to that case, hence defusing its challenge potential. In the cases examined in the next section, the meaning of the individual case is altered in order to fully reconcile it with a generalisation.

Altering the meaning of the individual case. Separating practices do not allow participants to pursue the applicability of a generalisation to the individual case invoked against it. In order to pursue this outcome, they employ two other practices: altering the meaning of the individual case (proposing that its pattern actually supports the generalisation) and specifying the generalisation (thereby resolving its apparent inconsistency with the individual case). This section focuses on the former. 
Before extract (10) (TC data), the group have been discussing Grazia's relapse into drug use. Roberto, the facilitator, recommends that Grazia become aware of the mechanisms triggering her desire for drugs (lines 1-2). Expanding his recommendation, Roberto uses a generalisation, proposing that desire to use drugs is a learned response that environmental triggers can set off (lines 4-6).

(10) (IntV6 51:58; TC data) 'Television'

Two facilitators, Roberto (F-Rob) and Marta (F-Mar), and one client, Cristina (C-Cri), speak in this extract. Three other clients, including Grazia, are present.

1 S-Rob: Cioè \#no::n\# eh (.) perché co个sì hai anche $>$ la possibilità < di I.mean not PTC because so have-2s also the possibility of 'I mean ((\#not\#)) uh (.) because in this way you also have >the'

2 ragiona:re su (.) quando si attivano queste situazioni qua? reason-INF on when IM activate-3P these situations here 'opportunity< to reflect on (.) when these situations activate themselves"

$3+($. c-gra: $\quad+$ nods

4 S-Rob: .hhh (0.4) Che ognu:no ha delle sue::: modalità di attivazione. that each have-3s some their modalities of activation '.hhh (0.4) That everyone has their own modes of activation.'

5 Quello che diceva la Marta no? Ci sono de'le .hhhhh delle cose what that say-IPF the NAME no EX be-3S some some things 'Like Marta was saying right? There are things ((one has))' <apprese> che in certi mome:nti scattano. learned REL in some moments spring-3P 'learned that sometimes kick in.'

Roberto's statement is designed as a generalisation through the reference term ognuno 'everyone' (line 4) and the impersonal construction ci sono delle cose apprese 'there are things ((one has)) learned' (line 6). Other features restrict the generalisation to drug users: the context of the talk (about Grazia's relapse) and the focus of Roberto's turn (on mechanisms leading to drug use; the euphemistic queste situazioni 'these situations' (line 2) is hearable as referring to desire to use drugs within the ongoing discussion). The generalisation has moral relevance: by inviting Grazia to become aware of the circumstances that can trigger a desire to use drugs, 
Pino (2021) - Challenging generalisations

Roberto mobilises the ethos of personal responsibility that characterises the therapeuticcommunity approach (Pearce \& Pickard 2013).

Cristina, a client, treats Roberto's statement as a generalisation by orienting to its implications for her own case. She produces an applicability challenge by reporting that sometimes she experiences a need to use drugs without there being any environmental triggers (lines 8-9).

(11) Direct continuation of (10): 'Television'

7

$(0.4)$

8 C-Cri: Be:h >oddio< però a me succede anche (.) magari guardando well oh.god but to 1S.A happen-3S also maybe watch-GER

'Well oddio but it also happens to me (.) maybe watching'

9 la televisione eh.

the television PTC

'the television right.'

10 S-Rob: ${ }^{\circ} \mathrm{Ce}:$ rto. ${ }^{\circ}$

certainly

${ }^{\circ}$ Of course. ${ }^{\circ}$

11 S-Rob: Ma è [così?]

but be-3s so

'But that's how it is?'

12 C-Cri: [Cioè:]: n:on mi sta parlando nessuno.

I.mean not 1S.D stay-3s speak-GER nobody

'I mean no one is talking to me.'

13

[Non mi sta caga[ndo nessuno, e::]

not 1S.D stay-3S shit-GER nobody and

'No one is paying attention to me, and'

14 S-Rob: [> $\uparrow$ No no.<

[Ci possono essere] SCE::NE_

no no

EX can-3P be-INF scenes

> $\uparrow$ No no. $<$

There can be SCE::NES_'

15 S-Mar: ${ }^{\circ} \mathrm{Mm} .^{\circ}$

PTC

${ }^{\circ} \mathrm{Mm} .{ }^{\circ}$

16 S-Mar: $\left[{ }^{\circ} \mathrm{S}: i^{\circ}{ }^{\circ}\right.$

yes

"Yes. ${ }^{\circ}$ 
Pino (2021) - Challenging generalisations

17 S-Rob: [>No no.< Ma queste cose sono[: provate, no no but these things be-3P prove-PSPT

'>No no. $<$ But these things have been demonstrated,'

Cristina's Beh oddio però a me succede anche 'Well oddio but it also happens to me' (line 8) frames her action as an applicability challenge; she constructs her case as not conforming to Roberto's generalisation. She reports that she experiences a desire to use drugs whilst watching the television (line 8-9), that is, in a mundane situation. Cristina's challenge manages some moral implications of Roberto's generalisation: if desire to use drugs is not determined by identifiable triggers, then the clients cannot be held accountable for managing or avoiding those triggers.

Roberto treats Cristina's case as confirming the generalisation, through Certo 'Of course' and $M a$ è così 'But that's how it is' (lines 10-11). Cristina pursues treatment of her case as disconfirming the generalisation by insisting that she experiences a desire to use drugs in circumstances devoid of triggers (lines 12-13). Roberto further insists that Cristina's case confirms the generalisation (lines 14 and 17; in line 14, he starts to propose that some scenes on television can work as triggers, and he fully articulates that position later, in data not shown). Therefore, Roberto supports the generalisation without modifying it; the outcome is to alter the meaning of Cristina's case (i.e. according to Roberto, Cristina's desire to use drugs IS set off by identifiable triggers).

With one exception (not shown here), it is the facilitators who use the practices examined in this section. They thereby enact their prerogative to offer (re)interpretations of the clients' cases by drawing upon institutionally relevant frameworks. Roberto's invocation of scientific evidence embodies such an 'expert role' (queste cose sono provate 'these things have been demonstrated', line 17).

In (10) and (11), the re-interpretation of a client's case is conveyed indirectly, at least initially, by treating it as confirming the generalisation ('Of course', 'But that's how it is') and by defending the generalisation in a way that concurrently confirms its applicability to Cristina's case (lines 14 and 17 in (11)). By contrast, in extract (12) below (BRV set), a facilitator explicitly re-interprets a client's case. Before (12), the group have discussed changes that grief brings in bereaved people's lives (data not shown). Jeanne, the facilitator, extends this line by proposing that the experience of bereavement has made the clients "new human beings" (lines 3-4) and by further commenting that this is "strength" (line 6). Admittedly, this proposal is different from the generalisations seen previously. It is nominally about the co- 
present clients and does not contain lexical elements suggestive of a generalisation. Nevertheless, contextual elements alongside the focus of Jeanne's turn indicate a generalisation in progress. Before the extract, Jeanne has read part of a book on bereavement and has proposed that it applies to the clients (generally, as a group; data not shown). Her intervention at lines 1-8 is part of that project: a generalised proposal about the meaning of grief, which applies to the clients as members of the category of bereaved people. It is not grounded in considerations about anyone's individual circumstances.

(12) (BRV 3-2 595; BRV data) 'Not strong'

One volunteer facilitator, Jeanne (F-Jea), and three clients, Jim (C-Jim), Rita (C-Rit), and Sam (C-Sam), speak in this extract. Four other clients and another volunteer are present.

1 F-Jea: $\quad<$ In th个rough > (0.4) for many $>$ I don't know if you'd agree, but<

2 <through> the strength and the love you had for your (.) people you've

3 los:t, h your loved ones, .hh (0.2) you have become (0.7) new human

4 beings [you've become $\uparrow$ di- [you're different] human=

5 C-Jim: [.hh [Oh absolutely. ]

6 F-Jea: =be[ings. (And I ] think [it's strength?)

7 C-Jim: [Absolutely. ] [Um-

8 ???: (Mm)

9 C-Rit: Well I think ((charity name omitted)) is the glue that holds £us all£

10 to[g(h)ether.

11 ???: $\quad[\mathrm{Mmhhh}[\underline{\mathrm{mm}}$ :

12 C-Jim: [Y $\underline{\text { eah }}$ ?

13 C-Rit: And

14 C-Jim: A[bsolutely.

15 C-Rit: [and when we are down, (.) we- we know that when we come here .hhhh uh 16 we can talk(e) about it. And (0.3) the glue (.) warms us. And $\uparrow$ keeps us

$17 \quad[£ \uparrow$ upright?£

18 F-Jea: [Really:? O:[::h.

19 C-Rit: [instead of falling on the flo(h)or

20 ???: $\mathrm{Mm}:=$

21 ???: $\quad \underline{M m}$

22 F-Jea: Oh bless you?= 
Jim, a client, agrees with Jeanne's proposal (lines 5 and 7). Rita, another client, orients to the possible compliment at the end of Jeanne's turn (line 6). Compliments mobilise crosscutting preferences (Pomerantz 1978; Schegloff 2007c). In line with a pattern documented in previous research, Rita manages the multiple constraints associated with those preferences by redirecting the praise to the organisation to which the support group belongs (lines 9-10, 1517, and 19). Jim agrees (lines 12 and 14) and Jeanne expresses appreciation (lines 18 and 22). Sam (a client) then produces an applicability challenge in (13).

(13) Direct continuation of (12): 'Not strong'

23 C-Sam: =I mean people say to me I'm $\uparrow$ stro:ng. (0.2) But

24 I don't see me. (0.2) As a strong pe:rson.=

25 F-Jea: =You never $\uparrow$ do:

$26 \quad(0.2)$

27 F-Jea: Yeah.

28

29 C-Sam: And I've- $\uparrow$ know I'm not strong.

30 F-Jea: Mm:.

$31 \quad($.

32 C-Sam: But I've had to be strong. I'm not- (0.2) I didn't have any <choice.>

33 F-Jea: Mm.=

34 C-Sam: =That's how I thi:n[k.

35 F-Jea: $\quad[\mathrm{Mm}$.

36 C-Sam: >I didn't have any choice? $<>$ I've had to $<(0.3)$

37 F-Jea: But you get > out of bed in the morning < you put one foot >in front of

38 the other, $<$ then you take a breath one after the other, and that

39 is strength.

Unlike the other cases in this article, Sam's challenge is not adjacent to the generalisation. Sam's "I mean people say to me I'm stro:ng” (line 23) nevertheless resonates with Jeanne's generalisation about the clients" "strength" (at line 6 in (12)). Sam contests the applicability of that generalisation to her own case (lines 23-24). Jeanne nevertheless does not treat this as challenging her generalisation (lines 25 and 27), possibly because Sam's "I don't see me as a strong person" allows for the possibility that she IS strong (although she does not 'see herself' as such). Sam further contests the idea that she is strong, this time through the 
unequivocal "[I] know I'm not strong" (line 29), followed by further articulation of her case (lines 32-36). At this point, Jeanne offers a re-interpretation of Sam's case, pursuing the view that she IS strong (lines 37-39). "But" frames Jeanne's turn as disagreeing with Sam's viewpoint. This operation reflexively defends the applicability of Jeanne's generalisation to Sam's case (and, concurrently, its general validity).

The practices examined in this section embody facilitators' prerogative to proffer interpretations of clients' experiences. Here, we see the impact of generalisations (and their 'mapping' potential; Pollner \& Stein 1996) at its maximum. Not only do facilitators defend generalisations and the actions they implement, but they also use them to re-interpret the individual cases that have been invoked against them - at the cost of disagreeing with the clients about the meaning of their own experiences. This enables facilitators to reflexively pursue therapeutic and educational goals. In these cases, the circle is closed, with discrepant cases finding their place within the interpretive framework of a generalisation.

Specifying the generalisation. An alternative way of reconciling a generalisation and an individual case is to further specify the generalisation. In my collection, this solution is mobilised after a generalisation has encountered protracted challenges. Extract (14) is a continuation of extract (5) and is presented here as context for the subsequent response to a challenge in extract (15). Lidia further challenges Enrico's generalisation (lines 28-31).

(14) Direct continuation of (5), line 27 repeated: 'Wrong people'

27 C-Enr: [Quello che ho fatto venire [qua.

that-M who have-1S make-PSTP come-INF here

'The one that I took here.'

28 C-Lid:

[Cioè: (.)

I.mean

'I mean (.)'

29

e-e >quindi non è< che perché frequenti ca:ttive

and and so not be-3s that because hang.out.with-2s bad

'and-and >so it's not $<$ that because you hang out with some bad'

30

compagnie, perché sei $\uparrow$ tu che vai

companies because be-2S $2 \mathrm{~S}$.N who go- $2 \mathrm{~S}$

'company, because it is $\uparrow$ you who go' 
Pino (2021) - Challenging generalisations

31

con quelle per[sone.]

with those persons

'with those people.'

32 C-Enr:

[Sì̀ ma] infatti [ ma : : ]

yes but indeed but

'Yes indeed bu::t'

33 C-Lid:

[Non è che] (è) la cattiva compagnia.

not be-3s that (be-3s) the bad company

'It's not the bad company.'

34

.hh (Ah) ma anche a me non han mai fatto mancare niente

(oh) but also to 1S.A not have-3P never make-PSTP lack nothing

'.hh (Oh) they didn't deprive me of anything either'

35

io avevo <tutto.>

1S.N have-IPF.1s everything

'I had <everything.>'

$36 \quad(0.2)$

37 C-Lid: .hh Però mi mancava qualcos'â:Itro.

but 1S.D lack-IPF.3s something=else

'.hh But I was missing something else.'

38

S[i vede $\uparrow$ io son andata- ]

IM see-3S 1S.N be-1S go-PSTP

'Clearly $\uparrow$ I went-'

39 C-Enr: [Sì ma dopo sei tu che vuoi] comunque.

yes but then be-2s 2 S.N who want-2s anyway

'Yes but then it's you who wants ((it)) anyway.'

40 C-Lid: Eh ma (eh) ce:rrto.

PTC but (PTC) certainly

'Right but of course.'

41 C-Enr: Appu:nto

indeed

'Indee: $\mathrm{d}$ '

Enrico agrees with Lidia's position and then projects an objection ( $m a$ 'but', line 32), which he abandons when Lidia continues her turn to further challenge Enrico's generalisation (line 33). Lidia invokes her own individual case to propose an alternative explanation for drug use (at line 38, before relinquishing the floor after Enrico has started a turn in overlap, Lidia 
appears to be on her way to saying that SHE decided to start using drugs, rather than being led to it by others). Here, Lidia explicitly manages some moral implications associated with Enrico's generalisation: she treats it as detracting from an ethos of personal responsibility, which she concurrently endorses (lines 28-31, 35-38). Enrico supports that ethos (line 39); however, he designs his own endorsement as independent, rather than as an agreement with Lidia. Lidia resists this by treating Enrico's point as obvious (line 40); Enrico does the same at line 41. After an 0.7-second silence (extract (15), line 42), Enrico extends his turn, now SPECIFYING his generalisation.

(15) Direct continuation of (14): 'Wrong people'

42

$(0.7)$

43

C-Enr: Ma no:n penso che sia sub- da subito così.

but not think-1S that be-SBJ.3S (immediately) from immediately so 'But I don't think it's like that from the start.'

44

45 C-Lid: .hh

46 F-Mar: tk.hh ${ }^{\circ} \mathrm{Si}^{\circ}$ forse:- (0.7) magari (.) se ti tro:vi in una yes maybe perhaps if 2S.RFL find- $2 \mathrm{~S}$ in a 'tk.hh ${ }^{\circ} \mathrm{Yes}^{\circ}$ maybe:- (0.7) perhaps (.) if you find yourself' compagnia (.) che:: .hh .h (0.3) e::h fa u:so::, company REL PTC make-3S use 'in a group of people (.) who .hh .h (0.3) e::h are using,' e tu sei in un momento particolarmente difficile:, and $2 \mathrm{~S} . \mathrm{N}$ be-2S in a moment particularly difficult 'and you are going through a particularly difficult time,'

49 C-Lid: Mm:

PTC

'Mm:.'

$50 \quad$ (.)

51 F-Mar: è più facile, be. $3 \mathrm{~s}$ more easy 'it's easier,'

Having supported the viewpoint that one is responsible for using drugs ((14), line 39), Enrico's non penso che sia da subito così 'I don't think it's like that from the start' ((15), line 
43) qualifies that position. Enrico suggests that people initially do not decide to embrace a drug-user lifestyle; that decision only comes later. With this, Enrico reintroduces his earlier generalisation (stated in extract (1), lines 11-12) whilst respecifying the conditions of its applicability. Enrico respecifies socialisation with the 'wrong people' as the first step in a drug user's journey. This operation preserves the generalisation and the explanation it implements whilst accommodating Lidia's viewpoint on personal responsibility (i.e. one becomes responsible for choosing a drug-user lifestyle later on). This analysis is supported by Marta's subsequent intervention.

Marta, a facilitator, supports Enrico's generalisation by proposing that socialising with drug users can provide the initial occasion for drug use (lines 46-51). She renews this position as a generalisation (although mitigated with 'maybe' and 'perhaps', line 46) through the generic 'you' (line 46; the pronoun is dropped in the original language, but the verb is conjugated in the singular second-person form). Crucially, Marta orients to Enrico's operation of respecifying the generalisation by further extending that operation. Marta proposes a circumstance in which other people's influence can lead someone to using drugs (se... tu sei in un momento particolarmente difficile 'if... you are going through a particularly difficult time', line 48). Adding this contingency, alongside the further qualification that interacting with drug users makes someone's drug use più facile 'easier' (rather than certain; line 51), allows Marta to accommodate possibly discrepant cases. For example, Lidia's friend, whose case Lidia had invoked (extract (2)), might be someone who was not going through a difficult time in her life when she was exposed to other people's drug use.

Specifying a generalisation has a concessionary quality. It pays deference to the expectation that individual cases should not be misrepresented, and it does so by specifying the conditions of applicability of a generalisation in order to achieve a better fit. An outcome of this process is that a position is defended at the cost of limiting its applicability; a generalisation is reduced to an extensive description that applies to many, but not all members of a category. As in other cases, we see that a challenge can be successful in limiting the scope of applicability of a generalisation.

\section{DISCUSSION}

Generalisations help people navigate a problem of experience (Heritage 2011) that is particularly salient within support-group interactions. This involves conveying perspectives on others' experiences (through explanations, interpretations, and evaluations) without commenting on them directly. Generalisations convey claims that apply to participants 
indirectly or by implication, by virtue of their membership in the category to which a generalisation applies. The analyses presented here therefore document a way in which delicate actions are formulated in cautious ways.

Generalisations draw on categorisations and the common-sense cultural understandings that are bound to them. These are powerful resources within support-group interactions. Although the present study has been limited to two types of support groups, it has identified similar patterns across them, suggesting that people interacting within diverse therapeutic settings (and across different national and linguistic contexts) draw on category memberships as sense-making and action-mobilising resources (also see Sacks' (1992) analyses of grouptherapy sessions for adolescents). Identifying as a member of a social category (such as a bereaved person or someone with a past of drug misuse) grants participants access to interpretive resources to make sense of their experiences.

However, use of categorisations is not without dangers: there is always the risk of being labelled through generalisations that attribute some undesired characteristic to each member of the category. Settling these matters is the outcome of social negotiations. Members may wish to retain control over which generalisations will apply to their category, as opposed to having them assigned by those who are not recognised as members (see Sacks' (1992) analysis of the self-administered category 'hotrodder' as an alternative to the category 'adolescent', which is administered by adults). Additionally, the present analyses show that those who identify as members do not always agree over which generalisations should be applied to the category. Finally, the generalised ways in which members of a category are defined are likely to be subject to subsequent negotiations and revisions over time.

To get a sense of how these phenomena are unlikely to be unique to the membership categories examined in this study, it is useful to consider the case of autism. People who have been diagnosed with autism spectrum disorder report that the diagnosis brings about a sense of belonging to a group of people who share similar experiences (Lewis 2016). This can be contrasted with a popular quote by autism expert Stephen Shore: 'If you've met one person with autism, you've met one person with autism'. 5 He further explained in an interview:

This quote emphasizes that there is great diversity within the autism spectrum. While the commonalities of people on the autism spectrum include differences in communication, social interaction, sensory receptivity, and highly focused interests, it's important to understand that the constellation of these characteristics blends together differently for each individual. (Lime Connect 2018) 
I take Shore's statement to embody the tension I investigated in this study. It is clear that in several areas of social life people value identifying as members of social categories, and that they use the sense-making and action-mobilising resources that those memberships afford them. However, people also protect themselves from unwelcome generalisations that the use of categorisations can generate. My analyses have documented a procedure for doing so: invoking a single case that does not conform to a generalisation. This practice mobilises the normative expectation that the diversity of experiences within a category should not be erased. The fact that the invocation of a single discrepant case is sufficient to challenge a generalisation and the action it implements is a testament to the power of individuality, which participants leverage to limit the pervasiveness of generalised understandings of the members of a category.

Prior research has consolidated our sense that membership categorisation is a pervasive aspect of the organisation of social interaction (Sacks 1992; Schegloff 2007a; Stokoe 2012). Sacks' (1992) famous proposal was that categories are 'protected against induction'. My analyses reinforce this idea: when a generalisation is challenged, various forms of damage control are deployed to protect the generalisation and the action it implements. However, this does not appear to be the entire story. Sacks (1992) further proposed:

there are things like the usual categorial terms - 'males', 'females', 'Democrats', etc.for which one can say 'Democrats do X', and if some Democrats don't, it doesn't affect the intended correctness of the term. It's not that a Member would go about complaining about a statement made with the categorial, in terms of 'I can show you one of them who isn't that way', and then everybody would figure that they'd have to remove the remark or apologize for it, etc.' (1992:550)

My analyses support a different conclusion: people CAN AND DO complain about how a generalisation misrepresents a single case within the category to which the generalisation applies. When they do so, a discrepancy is generated, which invites resolution. The challenges I identified occasion forms of damage control aimed at reconciling the chasm between a generalisation and the individual case that does not conform to it. Although the positions and actions that generalisations embody are usually reaffirmed following a challenge, their defence sometimes comes with a respecification of the scope of their applicability. As a result, generalisations are sometimes reduced to extensive statements that apply to many, but not all members of a category. The invocation of a single discrepant case can, therefore, be successful 
in promoting a change in how generalised perspectives on the members of a social category are deployed. It is possible that, in these exchanges, we are observing one of the ways in which cultural changes are brought about on a cumulative basis-by challenging the use of a generalisations and the actions they implement in situated, contextualised occurrences.

\section{APPENDIX: TRANSCRIPTION CONVENTIONS AND GLOSS ABBREVIATIONS}

\begin{tabular}{|c|c|}
\hline , & slightly upward intonation \\
\hline$?$ & upward intonation \\
\hline . & falling intonation \\
\hline- & level intonation \\
\hline [ & overlapping talk begins \\
\hline ] & overlapping talk ends \\
\hline$(0.8)$ & silences in tenths of a second \\
\hline (.) & silence less than two-tenths of a second \\
\hline wo::::rd & lengthening of the sound just preceding \\
\hline wo- & abrupt cut-off or self-interruption of the sound in progress \\
\hline word & stress or emphasis (usually conveyed through slightly rising intonation) \\
\hline$\uparrow \downarrow$ & marked pitch rise or fall \\
\hline$=$ & latching \\
\hline (word) & best estimate of what is being said \\
\hline hhh & hearable aspiration \\
\hline hhh & in-breath aspiration \\
\hline w(h)ord & aspiration internal to a word \\
\hline+ & the point where a visible behaviour (e.g. a nod) starts \\
\hline$(($ words $))$ & transcriber comments \\
\hline${ }^{\circ}$ word $^{\circ}$ & quieter or softer talk \\
\hline WORD & louder talk \\
\hline$>$ word $<$ & faster or rushed talk \\
\hline$<$ word $>$ & slower talk \\
\hline$<$ word & immediately following talk is jump-started \\
\hline$£$ word $£$ & talk delivered with a smiley voice quality \\
\hline \#word\# & talk with a creaky voice quality \\
\hline
\end{tabular}


Pino (2021) - Challenging generalisations

word the bolded consonant is produced more sharply than it normally would

$\begin{array}{llll}\text { GLOSS ABBREVIATIONS } & & \\ 1 & \text { first person } & \text { INF } & \text { infinitive } \\ 2 & \text { second person } & \text { IPF } & \text { past imperfect } \\ 3 & \text { third person } & \text { M } & \text { masculine } \\ \text { A } & \text { accusative } & \text { N } & \text { nominative } \\ \text { CND } & \text { conditional } & \text { P } & \text { plural } \\ \text { D } & \text { dative } & \text { PTC } & \text { particle } \\ \text { EX } & \text { existential } & \text { PST } & \text { past } \\ \text { F } & \text { feminine } & \text { PSTP } & \text { past participle } \\ \text { G } & \text { genitive } & \text { REL } & \text { relativiser } \\ \text { GER } & \text { gerund } & \text { RFL } & \text { reflexive } \\ \text { IM } & \text { impersonal } & \text { S } & \text { singular } \\ \text { IMP } & \text { imperative } & \text { SBJ } & \text { subjunctive }\end{array}$

\section{NOTES}

* I would like to thank two anonymous reviewers for their helpful comments on this article. My gratitude also goes to Rein Sikveland for commenting on an early version of this article.

Work on the TC data was funded by the People Programme (Marie Curie Actions) of the European's Union Seventh Framework Programme (FP7/2007-2013) under REA grant agreement no 626893. The contents of this article reflect only the views of the author and not the views of the European Commission.

${ }^{1}$ Ethical approval for the collection and publication of the TC data was granted by the Research Ethics Committee of the Faculty of Medicine and Health Sciences of the University of Nottingham (E10042014 SoHS INTERACT). Ethical approval for the collection and publication of the BRV data was granted by Ethics Approvals (Human Participants) SubCommittee of Loughborough University (R16-P003). Participants provided written informed consent to publish the transcripts. All names used in the transcripts are pseudonyms. The Italian 
Pino (2021) - Challenging generalisations

transcripts contain three lines: original Italian, interlinear glosses, and English idiomatic translation.

${ }^{2}$ I want to thank an anonymous reviewer for making this point about this extract as well as pointing out the centrality of moral considerations in the interactions examined in this article.

3 These change-of-state tokens (Heritage 1984a) stop short of accepting Amy's clarification and might thereby imply continuing lack of alignment on Donald's part.

${ }^{4}$ A more idiomatic translation for 'how these situations activate themselves' would be 'how these things happen'. In this case, I chose to retain the Italian phrasing to help the reader grasp the point Roberto is making, on how environmental triggers can 'activate' some responses (such as a desire to use drugs), which is salient for how the sequence runs off.

${ }^{5}$ I'd like to thank Sam Hope for making me aware of this.

\section{REFERENCES}

Auburn, Timothy (2005). Narrative reflexivity as a repair device for discounting 'cognitive distortions' in sex offender treatment. Discourse \& Society 16:697-718.

Billig, Michael (1985). Prejudice, categorization and particularization: From a perceptual to a rhetorical approach. European Journal of Social Psychology 15(1):79-103.

Drew, Paul (2018). Inferences and indirectness in interaction. Open Linguistics 4:241-59.

Edwards, Derek (1991). Categories are for talking: On the cognitive and discursive bases of categorization. Theory \& Psychology 1(4):515-42.

Edwards, Derek (1997). Discourse and cognition. Thousand Oaks, CA: SAGE.

Heritage, John (1984a). A change-of-state token and aspects of its sequential placement. In J. Maxwell Atkinson \& John Heritage (eds.), Structures of social action: Studies in conversation analysis, 299-345. Cambridge: Cambridge University Press. (1984b). Garfinkel and ethnometodology. Cambridge: Polity Press.

(2011). Territories of knowledge, territories of experience: Empathic moments in interaction. In Tanya Stivers, Lorendza Mondada, \& Jacob Steensig (eds.), The morality of knowledge in conversation, 159-83. Cambridge: Cambridge University Press.

Hester, Stephen, \& Peter Eglin (1997). Membership categorization analysis: An introduction. In Stephen Hester \& Peter Eglin (eds.), Culture in action: Studies in membership categorization analysis, 1-23. Boston, MA: International Institute for Ethnomethodology and University Press of America. 
Pino (2021) - Challenging generalisations

Jefferson, Gail (2004). Glossary of transcript symbols with an introduction. In Gene H. Lerner (ed.), Conversation analysis: Studies from the first generation, 13-23. Philadelphia, PA: John Benjamins.

Kitzinger, Celia (2000). How to resist an idiom. Research on Language and Social Interaction 33(2):121-54.

Kübler-Ross, Elisabeth (1969). On death and dying. New York: The Macmillan Company.

Lerner, Gene H. (1996). Finding 'face' in the preference structures of talk-in-interaction. Social Psychology Quarterly 59(4):303-21.

(2013). On the place of hesitating in delicate formulations: A turn-constructional infrastructure for collaborative indiscretion. In Makoto Hayashi, Geoffrey Raymond, \& Jack Sidnell (eds.), Conversational repair and human understanding, 95-134. Cambridge: Cambridge University Press.

Lewis, Laura Foran (2016). Realizing a diagnosis of autism spectrum disorder as an adult. International Journal of Mental Health Nursing 25:346-54.

Lime Connect (2018). Leading perspectives on disability: A Q\&A with Dr. Stephen Shore. Online: https://www.limeconnect.com/opportunities_news/detail/leadingperspectives-on-disability-a-qa-with-dr-stephen-shore.

Logren, Aija; Johanna Ruusuvuori; \& Jaana Laitinen (2017). Self-reflective talk in group counselling. Discourse Studies 19(4):422-40.

Pearce, Steve, \& Hanna Pickard (2013). How therapeutic communities work: Specific factors related to positive outcome. International Journal of Social Psychiatry 59(7):636-45.

Peräkylä, Anssi, \& David Silverman (1991). Owning experience: Describing the experience of other persons. Text 11(3):441-80.

Pino, Marco (2018). Invoking the complainer's past transgressions: A practice for undermining complaints in therapeutic community meetings. Research on Language and Social Interaction 51(2):194-211.

Pollner, Melvin, \& Jill Stein (1996). Narrative mapping of social worlds: The voice of experience in alcoholics anonymous. Symbolic Interaction 19(3):203-23.

Pomerantz, Anita (1978). Compliment responses: Notes on the cooperation of multiple constraints. In Jim Schenkein (ed.), Studies in the organization of conversational interaction, 79-112. New York: Academic Press.

Raymond, Geoffrey, \& John Heritage (2006). The epistemics of social relations: Owning grandchildren. Language in Society 35(5):677-705. 
Pino (2021) - Challenging generalisations

Robles, Jessica S. (2015). Extreme case (re)formulation as a practice for making hearably racist talk repairable. Journal of Language and Social Psychology 34(4):390-409.

Sacks, Harvey (1984). On doing ‘being ordinary’. In J. Maxwell Atkinson \& John Heritage (eds.), Structures of social action: Studies in conversation analysis, 413-29. Cambridge: Cambridge University Press. (1992). Lectures on conversation, vol 1. Oxford: Blackwell.

Schegloff, Emanuel A. (2007a). A tutorial on membership categorization. Journal of Pragmatics 39(3):462-82.

(2007b). Categories in action: Person-reference and membership categorization. Discourse Studies 9(4):433-61.

(2007c). Sequence organization in interaction: A primer in conversation analysis $I$. Cambridge: Cambridge University Press.

Sharrock, W. W., \& Roy Turner (1978). On a conversational environment for equivocality. In Jim Schenkein (ed.), Studies in the organization of conversational interaction, 173-97. New York: Academic Press.

Sidnell, Jack, \& Tanya Stivers (2013). Handbook of conversation analysis. Boston, MA: Wiley-Blackwell.

Steinberg, Dominique Moyse (2004). The mutual-aid approach to working with groups: Helping people help one another. 2nd edn. Binghamton, NY: The Haworth Press.

Stokoe, Elizabeth (2009). Doing actions with identity categories: Complaints and denials in neighbor disputes. Text \& Talk 29(1):75-97.

(2012). Moving forward with membership categorization analysis: Methods for systematic analysis. Discourse Studies 14(3):277-303.

Whitehead, Kevin A. (2018). Managing the moral accountability of stereotyping. Journal of Language and Social Psychology 37(3):288-309.

Wootton, A. J. (1977). Sharing: Some notes on the organization of talk in a therapeutic community. Sociology 11:333-50.

Zimmerman, Don H., \& Melvin Pollner (1970). The everyday world as a phenomenon. In Jack D. Douglas (ed.), Understanding everyday life, 80-103. Chicago, IL: Aldine.

Address for correspondence:

Marco Pino

Loughborough University 
Pino (2021) - Challenging generalisations

Communication and Media

Brockington Building, Margaret Keay Rd

Loughborough, LE11 3TU

United Kingdom of Great Britain and Northern Ireland

m.pino@lboro.ac.uk 